\title{
Under the Strategy of Rural Revitalization, Agricultural Products Can Use Their Power to Spread the Value of "Live and Short Video"
}

\author{
Wu Yanfei
}

School of Digital Media, SiChuan University Of Culture And Arts, Mianyang, Sichuan, China. wyf15601693919@163.com

\begin{abstract}
Rural revitalization is an important strategic measure to solve the "three rural" issues in China in the new era. The rapid development of the Internet and the popularization of smart phones have provided technical support for more farmer groups to contact the media. New farmers rely on new media technologies and short video platforms 。 Improve farmers' living standards and promote rural economic development. At present, "Agricultural poducts , short video and Live" has become an important driving force for the overall promotion of rural revitalization. This article will analyze the advantages of "Live and Short Video" in solving the "three rural" problems and discuss the use of rural agricultural products in the context of the rural revitalization strategy. Strengthen the communication value of "live broadcast + short video" and analyze the optimization path for the development of rural agricultural products with the help of "Live and Short Video".
\end{abstract}

Keywords: Rural revitalization strategy; Agricultural products; County economy; Live and short video; communication value.

\section{乡村振兴战略下农产品借力 “直播+短视频”的传播价 值 吴雁飞}

四川文化艺术学院数字传媒学院, 绵阳, 四川, 中国 wyf15601693919@163.com

摘要:

乡村振兴是中国新时期解决”三农”问题的重要战略举措, 互联网高速发展, 智能手机普及, 为更多的农民群体 与媒介接触提供了技术支持, 新农人借助新媒体技术与短视频平台, 提升农民生活水平, 促进农村经济发展。 当前, “农产品+短视频+直播”的已经成为全面推进乡村振兴的重要动力, 本文将以乡村振兴战略为背景, 分析 “直播+短视频”解决"三农”问题的优势, 论述乡村农产品借力"直播+短视频”的传播价值以及探析乡村农产品借 力"直播+短视频"发展的优化路径。

关键词:乡村振兴战略;农产品; 县域经济; 直播+短视频; 传播价值

\section{1. 前言}

2021 年中国短视频用户规模预计达到 8.09 亿 (数据来源: 艾媒咨询), 市场规模预计达到 580 亿元 (数据来源: 中商情报网) 庞大的短视频用户数量与巨 大的市场规模正吸引着各大产业入驻短视频平台, 这
场由新媒体环境的变革而掀起的互联网经济发展的 风口, 正影响着人们的生产、生活方式和中国经济的 发展。三农”问题是中国农业农村发展以及乡村振兴 的重要工作, 尤其是在”直播+短视频”环境下, 农业 发展与互联网、大数据紧密结合, 为乡村振兴开辟了 新渠道、新出路。自党的十九大提出乡村振兴和品牌 
强农战略以来，中国的农业迎来了高质量、高速度的 发展新阶段, 推进农产品借力”直播+短视频”是切实 提高农产品价值和竞争力, 助力农民增收致富的重要 手段。

\section{2. “农产品+直播+短视频" 的传播优势}

"直播+短视频" 带货已经成为新型的线上营销模 式。以短视频蜀中桃子姐为例, 到 2021 年粉丝量 $2135.8 \mathrm{w}$ 的型现象级网红, 其创作的短视频在社交平 台的播放总量 2.5 亿, 且成为主流媒体点赞的文化输 出典型代表。冊庸置疑, “直播+短视频”已成为新时 期一个巨大的流量的风口。

\section{1"农产品+直播+短视频"聚焦产业赋能, 加 快实现产业融合。}

$5 \mathrm{G}$ 时代, “农产品+直播+短视频”已经深度参与 农业农村经济发展, 是传播最美乡村、传播农业品牌 及产品故事的重要推手, 为产业赋能, 为地区赋能。 ${ }^{1}$ 依托互联网新媒体平台与强大的产业布局, “农产品 +直播+短视频”在发展中不断探索新的营销模式, 不 断创新，运用科技智能化技术及智能化管理方式，以 农产品为主体, 以科技为载体, 构建了从产农、加工 商、带货人、商业智能化运营管理、智能物流管理到 智慧服务的全产业链的新型农产品销售模式。

党的十九大以来, 各地深耕细打造具有地标性的 土特产和品牌。县域农产品深耕一二三产业融合, 串 连起一条坚实的商业”壁垒”产业链, 深度融合”农产 品+直播+短视频”, 搭建农业、农村、媒体、市场跨界 融合平台, 多方产业联合共同打造县域 IP 精粹, 为 产业赋能, 为农户创收, 助推乡村振兴。

\section{2 以打造县域品牌为抓手，高效实现地区资 源优化配置。}

后疫情时期，为解决区域农产品滞销的问题，不 少县域级政府官员成为了地方产品的“代言人+推广 人”，借力”直播+短视频”实现农产品高质高效增收。 产农与企业, 供应商与供销商之间的合作将会实现产 品商业价值的最大化，也会带来品牌社会价值的增值。 乡村振兴战略下农产品借力“直播+短视频”不断拓展 我国农产品市场, 形成了具有中国特色的农业发展新 模式。

政府在发展地区农业经济上应该发挥统筹兼顾 的作用。在打造县域品牌建设上积极发挥其“指挥师” 的作用, 调动多方资源着力打造具有地标性的县域级 农产品品牌, 依托农博会、文化节、商品推介会等展 销品台, 借力”直播+短视频”展现农产品培植培育地、 加工地、储存地及物流运输链, 宣传地方风土人情,
体现农产品产业链各端的商业价值, 实现农产品”形 象”的提升和优化, 形成区域品牌效应, 使其在同类产 品中更具有优势及竞争力, 从而提高消费者粘性, 实 现地区资源优化配置。

\section{3 政媒企三方联手，吸引用户提升交互体验。}

在促进乡村振兴的大背景下, 明星、网红、KOL、 政府官员通过公益直播、短视频，帮助农民卖货，带 动新农人开播, 创作”三农”短视频。政府官员及专家 学者参与到创新话语体系, 改变以往政府官员传统姿 态，因其身份特有的公信力，增强了受众对农产品的 认可度。此外，明星、网红、KOL、政府官员的加入， 以“直播+短视频” 的形式帮助农民群体传播当地优 质农产品, 打造具有地方特色农产品牌, 各大主流媒 体，最大化发挥其公信力，帮助农民群体实现农业信 息对称，帮助产农高速高质脱贫。

贺娇龙，新疆伊犁文旅局局长，四川甘孜理塘县 国企员工丁真等, 这些具有地方特色的县域级的网红 借助”直播+短视频”拓展了农产品客户渠道，为乡村 振兴注入了流量, 提升了当地农产的直播销售质量, 为当地农户创收、增收起到了积极作用。

\section{3. 乡村农产品借力"直播+短视频"的传播价值}

在新媒体语境下, “直播+短视频” 俨然成为现代 传播的通用语言, 乡村网红达人在乡村振兴中扮演重 要角色, 通过“直播+短视频”真实展现乡村农产品培 育、培植情况和乡村生活的状态, 凭借着原生态的内 容输出吸引力众多网民的关注和点赞。头部乡村网红 在短视频创作领域形成了强势的洪流, 并且正在影响 着城市和乡村网民的精神世界, 为乡村振兴举个人及 团队之力, 在当地农村区域经济的发展发挥着重要作 用。

四川甘孜藏族青年丁真、桃子姐、张同学、刘大 我等新晋的头部乡村网红在短视频创作领域形成了 强势的洪流，并且正在影响着城市和乡村网民的精神 世界, 为乡村振兴举个人及团队之力, 在当地农村区 域经济的发展发挥着重要作用。

\section{1 经济价值}

“直播+短视频”的传播形式打破了城市与乡村的 地理隔膜, 让果蔬、鲜花、肉类等农产品的培育者有 了更广阔的展示空间和更多的展示机会, 以低成本, 高反馈, 开拓新市场, 经济增收。乡村头部网红凭借 自身的流量和优质的短视频内容输出, 聚集一批忠诚 度较高的粉丝，不仅能够形成稳定的流量，还能实现 长期的经济利益转化，他们通过短视频平台，通过直 播带货的形式将区域内的农产品推销给大众, 最终帮 助农村脱贫和完成农村经济产业升级。

2020 年末四川甘孜藏族小伙丁真凭借其"颜值" 冲上热搜榜, 成为“超级网红”, 目前已完成个人 IP 
品牌构建，丁真的发掘为四川甘孜地区的旅游持续性 发展、乡村文化的推广、当地农产品的销售起到了助 推器的作用。“直播+短视频”对当地旅游宣传, 旅游 形象的构建及旅游业的发展产生了巨大的影响。

\section{2 社会价值}

在“农产品+直播+短视频”的场景下, 农民群体作 为乡村形象传播的主体被赋予了更多更广泛的传播 权利, 成为了乡村话语的构建者和乡村故事的讲述者。 利用”直播+短视频”促进平衡城市文明与乡村文明, 增加文明互动与互构, 凭借短视频作品和农产品, 打 破传统的”乡村=落后、城市=发达”的固有思想, 转变 人们在传播过程中的固有刻板印象, 构建新时代现代 新农村的视听媒介文化, 激活乡村文化的现代社会价 值, 促进乡村物质文明与精神文明建设共进。

最近, “张同学” 的短视频火遍全网, 两个月的 时间实现了粉丝由零到千万的涨粉势头, 抖音账号昵 称张同学, 原名张凯, 来自于东北东村, 曾经从事短 视频创作, 有着一定的行业经验, “张同学” 的视频 没有明显的故事情节和故事发展脉络, 相当于生活类 $v \log$, 每一条视频均采用同样的 BGM《Aloha He ja He》 且已形成风格, 其快节奏的剪辑节奏和平民化的镜头 设计给用户带来轻松的观影体验, 看似 “粗粘” 的视 频内容背后映射出来城市人的孤独, 希望借助观看 “张同学” 的视频对朴实的乡村生活有了沉浸式的体 验。

“直播+短视频”的门槛较低, 一部手机加一个农 产品即可实现自主化就业, 在”十四五”期间, “直播+ 短视频”将会充分发挥其特有的优势, 扩大农民群体 的表达空间, 赋予这个群体更多的话语空间, 将新农 村现存的问题展露出来, 让更多的人参与乡村振兴, 肩负起社会责任。

\section{3 文化价值}

头部乡村网红之所以能获得网民的持续关注和 点赞, 并且成为一种特殊的文化现象, 其背后真正的 原因得益于网红与粉丝之间建立了一种情感共鸣的 关系。古风美食博主李子染是跨文化传播的典范, 她 能够成功在世界走红, 是以互联网“直播+短视频”为 平台, 以地方文化价值为灵魂。他所创作的短视频没 有宏大的制作, 没有过多的语言, 回归田园生活的内 容输出, 一方面给予那些背井离乡的外出学习和务工 的人员以思乡的慰藉, 产生共情心理, 另一方面, 为 那些远离乡村生活, 但有向往乡村田园生活的网民带 来了更多地新鲜感和沉浸式的体验感, 让他们通过观 看视频感受农村田园生活。

头部乡村网红建立了极具吸引力的特殊文化品 牌, 不断重构自我身份的认同, 借力”直播+短视频” 进行新农人形象的呈现和乡村农耕文明与现代商业 文明和高速发展的科技文明的构建, 为中国文化走出
去起到了积极推动作用。因此头部乡村网红在短视频 内容上应该更加注重以文化强国、树立文化自信为准 则, 积极构建优质短视频内容生态。

\section{4. 乡村农产品借力"直播+短视频”的发展优化 路径}

\section{1 拓宽盈利渠道, 借助 $M C N$ 力量。}

MCN (Multi-C Channel Network) 是指集合了 若干垂直领域且具有一定影响力的短视频专业内容 生产者 (PGC), 利用其自身天然优势和资源为其提供 较为专业的内容生产管理、内容运营、粉丝管理以及 实现商业变现等一系列专业化的服务的管理机构。也 可将 $\mathrm{MCN}$ 机构视为拥有并掌握头部网红的专业生产 机构。

目前, “农产品+直播+短视频”的发展仍在探索和 发展阶段, 不少短视频账号仍处在初级 UGC 阶段, 因 此我们还需调动多方力量, 如 $\mathrm{MCN}$ 机构, 与 $\mathrm{MCN}$ 机构 达成战略合作，创作出更多 “农产品十直播+短视频” 的新玩法, 由此借力平台提供免费的流量扶持、品牌 共建、策略扶持、内容变现等多元化的支持, 促进农 业转型、消费升级, 最终实现发展双赢。

\section{2 打造县域网红体制的个人 IP, 凸显文化特 色。}

2020 年文化和旅游部办公厅印发《关于统筹做 好乡村旅游常态化疫情防控和加快市场复苏有关工 作的通知中》, 明确指出, 要注重培养一批本地、本 村网络直播带货能人，扩大乡村土特产的直播销售。

打造县域网红体制的个人 IP 是以互联网、新媒 体、新平台、新农业、新营销为基础, 以新农人、网 红达人、新 IP 为主体, 以农产品、特色旅游产品、 非遗文创产品等县域乡村的农产品为资源, 利用”直 播+短视频”推广销售的新型商业模式。找准个人 IP 的角色定位, 借力”直播+短视频”推广农产品, 主播 是品牌形象的传播者, 因此主播需要找准自身的与品 牌形象相契合的点通过自我表现传递品牌精神、品牌 价值。 ${ }^{3}$ 从产品到场景到剧情再回归产品, 由产品展 现场景, 再有场景构建剧情, 再由剧情回归产品推广, 好的剧情可让产品与剧情自然衔接, 在“润物细无声 中”传播产品价值。视角互换, 沉浸式体验, 将有效 促成交易。

乡村振兴, 人才是关键。建设符合社会主义核心 价值观的网红培养机制, 制定科学的“网红”人才培养 方案, 优选当地极具潜力的新农人, 重点培育, 精心 包装，积极鼓励具有区域特色的新农人开播，打造区 域农产品代表人。 


\section{3 打造以地方网络为主体的商业矩阵}

打造以地方网络为主体的商业矩阵, 是以具有地 标性的品牌为中心, 拓展出产品矩阵, 账号矩阵, 平 台矩阵, 服务矩阵; 是以地方网红、新农人为中心, 搭建账号矩阵, 以大号带小号的方式形成矩阵, 内容 上实现产品研发 (新农人), 产品推广 (短视频+直播), 用户反馈 (消费者), 产品优化 (新农人) 完整的商 品闭环, 不断优化产品升级, 借助 “直播+短视频” 实现拉新、促活、留存和转化。

“农产品+直播+短视频”的商业模式 (优质的农产 品; 具有公信力的网红; 短视频账号定位 + 优质的内 容创作; 优质的传播渠道=流量杜杆; 运营团队) 具有 打造以地方网络为主体的商业矩阵的天然优势, 这种 裂变式的增粉模式无疑是当下短视频引流的最佳玩 法。 ${ }^{4}$

\section{5. 结论}

践行农产品借力”直播+短视频”的理念, 加快发 展地方农业经济, 共同构建”农产品+直播+短视频” 内容生态, 促进农业农村经济有序良性发展。通过“农 产品+直播+短视频” 把具有地方特色的农产品转化为 具有市场优势和竞争优势的商品, 强化地方县域文化 传承, 建设美丽乡村, 打造县域网红达人, 积极挖掘 具有地方特色的农耕文明、民族民俗风情和淳朴乡土 文化, 借此打好具有中国特色的历史牌、文化牌、风 俗牌, 讲好地标故事, 讲好农民故事, 讲好经济故事, 提升农产品价值、增加农民收入, 才能助力乡村振兴 战略的实施。

\section{REFERENCES}

[1]Yu Guoming.(2019) Communication Development in the 5G Era: Turning Points, Challenges, Opportunities and Missions,"Media Observation", 125:21-24

[2]ShiLei,HuangTingting.(2020)Emotional Commodities and Emotional Circulation: The Transmission Mechanism of "Three Rural" Short Videos. Editor's Friends, 143:46-47.

[3] Deng Yuanbing, Zhao Luhong.(2019)The city image communication strategy of short video platform based on SIPS mode-Taking the Douyin short video platform as an example ,China Editor, 152:56-58.

[4] Geng Ying.(2018) Model analysis of the diffusion of new media from the perspective of technology-resonance model and its verification. China Media Technology,186: 123-127. 